11 Evans N, Farkas A, Gilpin E, Berry C, Pierce JP. Influence of tobacco marketing and exposure to smokers on adolescent susceptibility to smoking J Natl Cancer Inst 1995;87:1538-45.

12 Feighery E, Borzekowski DL, Schoder C, Flora J. Seeing, wanting, owning: the relationship between receptivity to tobacco marketing and smoking susceptibility in young people. Tob Control 1998;7:123-8.

13 Ledwith F. Does sports sponsorship act as advertising to children? Health Educ J 1984;43:85-8.

14 Piepe AP, Charlton P, Morey J, Yerrell P, Ledwith F. Does sponsored sport lead to smoking among children? Health Educ J 1986;45:145-8.

15 Charlton A, While D, Kelly S. Boys' smoking and cigarette-brandsponsored motor racing. Lancet 1997;350:1474.

16 Altman DG, Levine DW, Coeytaux R, Slade J, Jaffe R. Tobacco promotion and susceptibility to tobacco use among adolescents aged 12 through 17 and susceptibility to tobacco use among adolescents aged 12 through 17 years in a na

17 Gilpin EA, Pierce JP, Rosbrook B. Are adolescents receptive to current sales promotion practices of the tobacco industry? Prev Med 1997;26:14-21.
18 Pierce JP, Choi WS, Gilpin EA, Farkas AJ, Berry CC. Tobacco industry promotion of cigarettes and adolescent smoking. JAMA 1998;279:511-5. 19 Redmond WH. Effect of sales promotion on smoking in US ninth graders. Prev Med 1999;28:243-50.

20 Aitken PP, Eadie DR, Hastings GB, Haywood AJ. Predisposing effects of cigarette advertising on children's intentions to smoke when older. $\mathrm{BrJ}$ Addiction 1991;86:383-90.

21 UK Parliament. Public bills before parliament. Tobacco Advertising and Promotion Bill. www.parliament.the-stationery-office.co.uk/pa/pabills.htm (accessed 19 Feb 2000).

22 Higgins V. Young teenagers and smoking in 1998: a report of the key finding from the teenage smoking attitudes survey carried out in England in 1998. London: ONS Social Survey Division, 1998.

23 House of Commons Health Committee. Second report. The tobacco industr and the health risks of smoking. Vol 1. London: Stationery Office, 2000.

(Accepted 16 February 2001)

\title{
Adverse events in British hospitals: preliminary retrospective record review
}

\author{
Charles Vincent, Graham Neale, Maria Woloshynowych
}

\begin{abstract}
Objectives To examine the feasibility of detecting adverse events through record review in British hospitals and to make preliminary estimates of the incidence and costs of adverse events.

Design Retrospective review of 1014 medical and nursing records.

Setting Two acute hospitals in Greater London area. Main outcome measure Number of adverse events. Results 110 (10.8\%) patients experienced an adverse event, with an overall rate of adverse events of $11.7 \%$ when multiple adverse events were included. About half of these events were judged preventable with ordinary standards of care. A third of adverse events led to moderate or greater disability or death. Conclusions These results suggest that adverse events are a serious source of harm to patients and a large drain on NHS resources. Some are major events; others are frequent, minor events that go unnoticed in routine clinical care but together have massive economic consequences.
\end{abstract}

\section{Introduction}

Retrospective studies of hospital case records in the United States and Australia have shown a substantial rate of adverse events, defined as unintended injuries caused by medical management rather than the disease process. The Harvard medical practice study found that $3.7 \%$ of hospital admissions led to adverse events. ${ }^{12}$ In $70 \%$ of these patients the adverse event led to slight or short lived disabilities, but in $7 \%$ the disabilities were permanent and in $14 \%$ they contributed to death. Similar rates were found in a study from Colorado and Utah. ${ }^{34}$ The quality in Australian healthcare study identified adverse events in $16.6 \%$ of admissions, half of which were considered preventable. ${ }^{5}$ This study included a wider range of adverse events of minor or moderate severity. Other methodological differences also exaggerate the difference between the United States and Australian figures. ${ }^{46}$ The Australian study estimated that adverse events accounted for $8 \%$ of hospital bed days and cost the Australian healthcare system $\$ 4.7 \mathrm{bn}$ a year. Adverse events also result in huge personal cost to the affected individuals, both patients and staff. ${ }^{7}$

The epidemiology of adverse events has not been studied in Britain. We report preliminary findings from a pilot study that examined the feasibility of applying United States and Australian methods and the potential value of a parallel study in the United Kingdom.

\section{Methods}

\section{Design and procedure}

The study was carried out at two acute hospitals in the London area. We reviewed 500 randomly drawn records from site 1 between July and September 1999 and 514 records from site 2 between December 1999 and February 2000. In both sites the index admissions studied occurred in two months in 1998, about a year before the review periods. We reviewed 273 (26.9\%) records from general medicine (including geriatrics), $290(28.6 \%)$ from general surgery, $277(27.3 \%)$ from orthopaedic surgery, and 174 (17.2\%) from obstetrics. Admissions to the four specialties studied in 1998-9 were 19397 in site 1 and 18335 in site 2. The proportions of admissions studied were $2.6 \%$ and $2.8 \%$ respectively.

\section{Review process}

The review team consisted of an experienced nurse who worked as project manager with four part time research nurses. A consultant physician acted as lead medical assessor, working with five part time surgical and obstetric colleagues, each of whom had been qualified for a minimum of 10 years. Each reviewer screened sets of notes under supervision until they were judged to be fully conversant with the review process.

The nurse reviewers used 18 predefined screening criteria to assess the case records. Records that

\section{Editorial by Alberti Letters p 548 \\ Reviews pp 562, 563 \\ Clinical Risk Unit, Department of Psychology, University College London, London WC1E 6BT \\ Charles Vincent professor of psychology Graham Neale consultant physician Maria \\ Woloshynowych research fellow \\ Correspondence to: C Vincent \\ c.vincent@ucl.ac.uk}

BMJ 2001;322:517-9

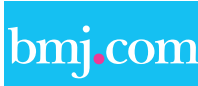

The criteria for adverse events and tables of results is available on the BMJ's website 
Table 1 Number of adverse events by specialty

\begin{tabular}{|c|c|c|c|c|c|}
\hline \multirow[b]{2}{*}{ Specialty } & \multirow{2}{*}{$\begin{array}{l}\text { No }(\%) \text { of } \\
\text { records } \\
\text { reviewed }\end{array}$} & \multicolumn{2}{|c|}{$\begin{array}{c}\text { No of patients with adverse } \\
\text { events detected }\end{array}$} & \multicolumn{2}{|c|}{$\begin{array}{c}\text { Total No of adverse events } \\
\text { detected }\end{array}$} \\
\hline & & $\begin{array}{l}\text { All (\% of } \\
\text { records) }\end{array}$ & $\begin{array}{c}\text { Preventable } \\
\text { (\% of events) }\end{array}$ & $\begin{array}{l}\text { All }(\% \text { of } \\
\text { records) }\end{array}$ & $\begin{array}{l}\text { Preventable } \\
\text { (\% of events) }\end{array}$ \\
\hline General medicine & $273(27)$ & $24(8.8)$ & $18(75)$ & $25(9.2)$ & $19(76)$ \\
\hline General surgery & $290(29)$ & $41(14.1)$ & $17(41)$ & $47(16.2)$ & $20(43)$ \\
\hline Obstetrics & $174(17)$ & $7(4.0)$ & $5(71)$ & $7(4.0)$ & $5(71)$ \\
\hline Orthopaedics & 277 (27) & 38 (13.7) & $12(32)$ & $40(14.4)$ & $13(33)$ \\
\hline Total & 1014 & $110(10.8)$ & $52(47)$ & $119(11.7)$ & 57 (48) \\
\hline
\end{tabular}

\section{Example of adverse event}

A 53 year old man with a history of stroke, multiple resistant Staphylococcus aureus infection, leg ulcers, and heart failure was admitted for treatment of venous ulceration and cellulitis of both legs. He sustained two adverse events:

1. Failure to manage the leg ulcers aggressively led to the development of osteomyelitis. He subsequently had below knee amputation of both legs.

2. Incorrect management of his urinary catheter resulted in necrosis of the tip of the penis. He had suprapubic catheterisation and developed an infection. The patient's hospital stay was extended by 26 days.

screened positive $(n=405)$ were then reviewed by clinicians, who identified any adverse events and completed a detailed questionnaire. The clinicians assessed the impact of each adverse event on the patient in terms of disability and additional bed days, likely cause, place and date of occurrence, type of adverse event (for example, whether related to a particular procedure or treatment), and preventability and recorded detailed clinical information. Records were reviewed once only, although difficult issues were resolved after duplicate review and discussion between two or more assessors. Criteria for adverse events are given on the $B M J$ 's website. A full description of the methods has been published. ${ }^{25}$ Copies of the British review forms are available from the authors.

\section{Results}

In all, $110(10.8 \%)$ of 1014 patients experienced an adverse event (table 1). However, some patients experienced multiple events, and the overall number of events was 119 (11.7\%). There was no significant difference in sex between patients who did and did not experience an adverse event. However, patients with adverse events were older than those who did not experience an adverse event $(\mathrm{P}<0.001$; see tables $\mathrm{A}$ and B on BMJ's website)

Seventy three $(66 \%)$ patients who suffered an adverse event had minimal impairment or recovered

Table 2 Estimated cost of adverse events (1999 values)

\begin{tabular}{lcccc} 
Specialty & $\begin{array}{c}\text { No of patients } \\
\text { with adverse } \\
\text { events }\end{array}$ & $\begin{array}{c}\text { Mean (SD) extra } \\
\text { bed days for all } \\
\text { adverse events }\end{array}$ & $\begin{array}{c}\text { Daily cost of bed } \\
(\mathfrak{(})\end{array}$ & $\begin{array}{c}\text { Total cost of } \\
\text { additional bed } \\
\text { days for study } \\
\text { sample (£1000s) }\end{array}$ \\
\hline General medicine & 25 & $4.87(5.67)$ & 171 & 20.8 \\
\hline General surgery & 47 & $6.07(12.52)$ & 282 & 80.4 \\
\hline Obstetrics & 7 & $3.57(2.88)$ & 305 & 7.6 \\
\hline Orthopaedics & 40 & $14.58(17.87)$ & 311 & 181.4 \\
\hline Total & 119 & $8.54(13.55)$ & - & 290.2 \\
\hline
\end{tabular}

within one month; 37 (34\%) patients developed an injury or complication that resulted in moderate impairment (21 patients; 19\%) or permanent impairment (seven patients; $6 \%$ ) or contributed to death (nine patients; 8\%). Overall, 53 (48\%) adverse events were judged preventable. The box shows an example of a patient who experienced serious adverse events.

The 119 adverse events resulted in a total of 999 extra bed days, of which $460(46 \%)$ were judged preventable and therefore could have been saved. Each adverse event led to an average of 8.5 additional days in hospital (range 0-70 days) with additional direct costs of 2290268 to the trusts concerned (table 2).

\section{Discussion}

Our pilot study has established the feasibility of conducting a major record review of adverse events in the United Kingdom. We found that $10.8 \%$ of patients admitted to hospital experience an adverse event, with an overall $11.7 \%$ rate of adverse events when multiple adverse events are included. About half of these events were judged preventable. A third of adverse events led to moderate or greater disability or death. Some adverse events are serious and are traumatic for both staff and patients. Others are frequent, minor events that go unnoticed in routine clinical care and yet together have massive economic consequences.

This study is primarily a pilot and has certain limitations. The study was small and based on only two hospitals. In addition, the case mix does not accurately reflect hospital practice. The specialties included in the review could have higher rates of adverse events than other specialties. Nevertheless, the specialties we chose constitute a large proportion of inpatient care.

Although we cannot extrapolate with any precision, our findings strongly suggest that adverse events are a serious problem in the NHS, as they are in the United States and Australia. We estimate that around $5 \%$ of the 8.5 million patients admitted to hospitals in England and Wales each year experience preventable adverse events, leading to an additional three million bed days. The total cost to the NHS of these adverse events in extra bed days alone would be around $£ 1$ bn a year.

\section{What is already known on this topic}

Substantial numbers of patients in hospital in the United States and Australia have been found to suffer adverse events

No data are available for the United Kingdom

\section{What this study adds}

In this pilot study about $10 \%$ of patients admitted to acute hospitals experienced an adverse event

A third of these events led to moderate or greater impairment

About half of the adverse events were preventable with current standards of care

Preventable adverse events could cost the NHS around $£ 1$ bn a year in terms of additional bed days 
In the United States and Australia retrospective case record analysis has provided the foundation and driving force for initiatives to reduce harm to patients and to make more efficient use of expensive hospital resources. Our findings indicate that a full national study would be justified in the United Kingdom, as indicated in the chief medical officer's recent report. ${ }^{8}$ We believe that the investigation should cover at least 20 general hospitals (of varying size and type) and include 500 representative case records from each hospital. This would yield around 1000 adverse events for detailed analysis. Such a study would provide reliable information on the numbers, types, and costs of adverse events occurring in NHS hospitals. This would allow the principal causes to be explored and specific risk reduction strategies to be identified and costed. The total cost of such a study would probably be equivalent to the money lost through preventable adverse events in less than eight hours in the NHS

We thank our international colleagues Bob Gibberd, John Hamilton, Bernie Harrison, Eric Thomas, and Ross Wilson for their time and support, and Alastair Gray for advice on economic aspects of the study. We also thank the clinical reviewers: Justice U-Lois, Sebastian Borges, Aubyn Marath, Deirdre Murphy, and Robert Downes; the nurse/midwife screeners: Jayne Moore, Jane Weaver, Sinéad Trainor, Marcia Persaud, and Katie Major; and the staff at the two trusts.
Contributors: $\mathrm{CV}$ designed and wrote the original research proposal. GN was lead clinician for the review. MW managed the project and was responsible for data analysis. All authors contributed equally to the final report. CV and GN are guarantors.

Funding: King's Fund, Nuffield Trust, London Region NHS Research and Development Programme, and the Dunhill Medical Trust. The views and opinions expressed in this article do not necessarily reflect those of these bodies

Competing interests: None declared.

1 Brennan TA, Leape LL, Laird NM, Hebert L, Localio AR, Lawthers AG, et al. Incidence of adverse events and negligence in hospitalised patients N Engl J Med 1991;324:370-6.

2 Leape LL, Brennan TA, Laird NM, Lawthers AG, Localio AR, Barnes BA et al. Incidence of adverse events and negligence in hospitalised patients: results of the Harvard medical practice study II. $N$ Engl J Med 1991;324:377-84

3 Gawande AA, Thomas EJ, Zinner MJ, Brennan TA. The incidence and nature of surgical adverse events in Colorado and Utah in 1992. Surgery 1999;126:66-75

4 Thomas EJ, Brennan TA. Errors and adverse events in medicine. In Vincent CA, ed. Clinical risk management:enhancing patient safety. 2nd ed. London: BMJ Publications (in press).

5 Wilson RM, Runciman WB, Gibberd RW, Harrison BT, Newby L, Hamilton JD. The quality in Australian health care study. Med J Aust 1995;163: 458-71.

6 Weingart SN, Wilson RMcL, Gibberd RW, Harrison B. Epidemiology of medical error. BMJ 2000;320:774-7

7 Vincent CA. Risk, safety and the dark side of quality. BMJ 1997;314 $1775-6$.

8 Department of Health. An organisation with a memory: report of an expert group on learning from adverse events in the NHS. London: $\mathrm{DoH}, 2000$.

(Accepted 27 November 2000)

\title{
Involving consumers in designing, conducting, and interpreting randomised controlled trials: questionnaire survey
}

\author{
Bec Hanley, Ann Truesdale, Andy King, Diana Elbourne, Iain Chalmers
}

\author{
Abstract \\ Objective To assess the extent to which consumers \\ are involved in the work of clinical trial coordinating \\ centres in the United Kingdom and the nature of \\ consumers' involvement in randomised trials \\ coordinated by these centres. \\ Design National surveys using structured \\ questionnaires with some open ended sections. \\ Setting 103 clinical trial coordinating centres in the \\ United Kingdom identified through a database \\ assembled in 1997 by the NHS clinical trials adviser. \\ Participants Named contacts at 62 coordinating \\ centres and investigators in 60 trials that were \\ identified as involving consumers. \\ Main outcome measures Number of coordinating \\ centres and number of trials in which consumers were \\ involved and the nature of consumers' involvement. \\ Results Of the 62 eligible centres, 23 reported that \\ consumers had already been involved in their work, \\ and most respondents were positive about this \\ involvement. 17 centres planned to involve \\ consumers. 15 centres had no plans to involve \\ consumers, but only four of these considered such \\ involvement irrelevant. Responses from investigators \\ about the 48 individual trials were mostly positive, \\ with respondents commenting that input from \\ consumers had helped refine research questions,
}

improve the quality of patient information, and make the trial more relevant to the needs of patients. Conclusions Consumer involvement in the design and conduct of controlled trials seems to be growing and seems to be welcomed by most researchers. Such involvement seems likely to improve the relevance to consumers of the questions addressed and the results obtained in controlled trials.

\section{Introduction}

There is substantial evidence that there are mismatches between the research that gets done and the research that patients would like to see done. ${ }^{1-3}$ This has led some to call for greater involvement of patients in the research process. ${ }^{45}$ Research designed to assess the effects of treatments and randomised controlled trials in particular seem especially likely to benefit from the involvement of consumers.

Both consumers and researchers are interested in involving consumers in clinical trials, but there has been little formal advocacy of such involvement in the United Kingdom. The 1998 guidelines on clinical trials from the Medical Research Council referred to the involvement of consumers only in an appendix, ${ }^{6}$ and the guidelines of the Association of the British Pharmaceutical Industry made no mention of consumer involvement. ${ }^{7}$ Most reports of trials do not make
Consumers in NHS Research Support Unit, Help for Health Trust Winchester SO22 5DH Bec Hanley director

Medical Statistics Unit, London School of Hygiene and Tropical Medicine, London WC1E 7HT

Ann Truesdale study coordinator Andy King computer programmer Diana Elbourne reader in health care evaluation

continued over

BMJ 2001;322:519-23

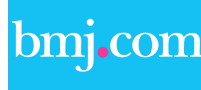

Additional information about the trials and the centres is available on the BMJ's website 